
\title{
Reseserch Suare \\ The Effects of Smoking, Regular Drinking, and Unhealthy Weight on Healthcare Utilization in China
}

\section{Changle Li}

Inner Mongolia Medical University https://orcid.org/0000-0001-7043-8284

\section{Zhengzhong Mao}

Sichuan University

Caixia Yu ( $\nabla$ cxcxyu@126.com )

Inner Mongolia Medical University

\section{Research article}

Keywords: Smoking, Regular drinking, Unhealthy weight, Healthcare utilization, China

Posted Date: December 11th, 2020

DOl: https://doi.org/10.21203/rs.3.rs-122510/v1

License: (1) This work is licensed under a Creative Commons Attribution 4.0 International License.

Read Full License 


\title{
The effects of smoking, regular drinking, and unhealthy weight on healthcare utilization in China
}

\author{
Changle $\mathrm{Li}^{1}$, Zhengzhong $\mathrm{Mao}^{2}$, Caixia $\mathrm{Yu}^{1}$
}

\begin{abstract}
AFFILIATION
1 School of Health Management, Inner Mongolia Medical University, Hohhot, China 2 School of Public Health, Sichuan University, Chengdu, China

\section{Correspondence to:}

Caixia Yu. School of Health Management, Inner Mongolia Medical University, Jinshan Economic Development Zone, Hohhot, China 010110.

E-mail: cxcxyu@126.com
\end{abstract}

\begin{abstract}
Background: The preventable risk factors such as smoking, harmful drinking, and unhealthy weight have contributed to the accelerated rise in non-communicable chronic diseases that are dominant drivers of health care use and spending in China. This study aimed to ascertain the effects of smoking, regular drinking, and unhealthy weight on healthcare utilization in China.

Methods: The database used in this study was obtained from the China Family Panel Studies (CFPS), and the final sample consisted of 63,260 adults in all the five waves of data collection. The fixed effects logistic regression model was used for the analysis.
\end{abstract}


Results: The current study found that among Chinese adults, current and former smokers were more likely to use outpatient and inpatient care compared to those who never smoked. Former smokers increased the odds of using outpatient and inpatient care than current smokers. Moreover, compared to healthy weight people, obese people increased the likelihood of using outpatient and inpatient care, and overweight people were more likely to be hospitalized. In contrast, people who regularly drank alcohol were less likely to use outpatient and inpatient care than non-regular drinkers.

Conclusion: This study ascertained the effects of smoking, regular drinking, and unhealthy weight on healthcare utilization in China using a five-waves of balanced panel data set. These results may have important implications for supporting the government to make healthcare resources allocation decisions.

Keywords: Smoking, Regular drinking, Unhealthy weight, Healthcare utilization; China

\section{Background}

National Report on Nutrition and Chronic Diseases of Chinese Population in 2015 showed that the estimated prevalences of current tobacco smoking, harmful drinking, and obesity among adults were $26.6 \%, 9.3 \%$, and $11.9 \%$, respectively [1]. The preventable risk factors such as smoking, harmful drinking, and unhealthy weight have contributed to the accelerated rise in non-communicable chronic diseases in China [2]. Chronic diseases are 
dominant drivers of health care use and spending [3]. The economic burden of chronic diseases was estimated to be $\$ 7.7$ trillion from 2010 to 2030 in China [4].

The difficulty of estimating the effect of smoking status on healthcare utilization has led to conflicting findings in the general population. Many studies reported that current and former smokers are associated with higher outpatient utilization than those who never smoked [5-9]. Interestingly, some studies found that current smoking has an association with fewer outpatient visits [10-12]. Therefore, more research is necessary to examine the relationship between smoking and outpatient utilization. The effect of smoking status on inpatient care utilization was found to be similar across a number of studies. Smoking status is associated with higher hospitalization for current and former smokers compared to never smokers $[7,10,11,13,14]$.

The findings are mixed on alcohol consummation affecting health care utilization. Some studies presented that problematic alcohol users are associated with higher healthcare utilization, including outpatient visits, emergency services, and hospitalization compared to abstainers $[15,16]$. In contrast, many studies found that alcohol users are associated with lower health care use than abstainers [14, 17-20].

Several studies have examined the associations between unhealthy weight and healthcare utilization. For example, some researchers found that overweight and obesity are positively associated with primary care utilization [21-23]. Moreover, overweight and obese people are significantly more likely to be hospitalized [24-25]. Furthermore, 
underweight patients increase the likelihood of hospitalization and visiting the emergency room compared to patients with higher body mass index [26].

Most studies reported the effects of smoking, drinking, and unhealthy weight on healthcare utilization using cross-section data. The main estimation methods included logistic regression, Poisson regression, negative binomial regression, and hurdle regression $[12,13,15,16,21,24]$. However, the choice variables of health-related behaviors are most likely to be considered endogenous in regression equations. One of the most frequent estimation techniques to address endogeneity bias in cross-sectional data is instrumental variables [27]. Due to the increased availability of longitudinal data, panel data models offer a solution to the endogeneity problem without resorting to instrumental variables. Panel data models can be used to control for time-constant unobserved heterogeneity and omitted time-varying variables [28].

To our knowledge, minimal information is available on health-related behaviors, unhealthy weight, and healthcare utilization in China $[8,29]$. Therefore, the objective of this study is to ascertain the effects of smoking, regular drinking, and unhealthy weight on healthcare utilization in China using a five-waves of balanced panel data set. This knowledge will allow us to better understand the underlying causes of healthcare utilization by smoking, regular drinking, and unhealthy weight, thus helping health policy decisionmakers make healthcare resources allocation decisions.

\section{Methods}

\section{Data source}


The database used in this study was obtained from the China Family Panel Studies (CFPS), launched by the Institute of Social Science Survey of Peking University. The CFPS is a general-purpose, nationally representative, longitudinal survey, including community, family, adult, and child questionnaires. The survey sample was drawn from twenty-five provinces and their administrative equivalents, representing $95 \%$ of the Chinese population. A multistage probability proportional to size sampling was used for the survey. The CFPS respondents are followed every two years, and the first wave in 2010 covered a sample of 14,798 households with 33,600 adults (above 16 years old), and four waves of full sample follow-up surveys in 2012, 2014, 2016, and 2018 covered 13,315 households with 35,719 adults, 13,946 households with 37,147 adults, 14,019 households with 36,892 adults, and 14,241 households with 32,669 adults, respectively. More details about the CFPS are available from Xie and $\mathrm{Hu}$ [30]. Only the adults responding to the full-length questionnaires in all waves were selected. The final analytic sample consisted of 63,260 adults (balanced panel data) in all the five waves of data collection.

\section{Dependent variables}

The current study measured healthcare utilization from two perspectives: outpatient care utilization and inpatient care utilization. Outpatient care utilization is a dummy variable that equals 1 if the individual self-reported an outpatient visit in the last two weeks and 0 otherwise. The CFPS question supporting this variable was: 'Did you visit a doctor in the past two weeks?'. Inpatient care utilization was also set as a dummy variable that equals 1 
if the individual self-reported being hospitalized in the past twelve months and 0 otherwise, based on the CFPS question: 'Have you been hospitalized in the past twelve months?'.

\section{Independent variables}

First, each adult was asked: 'Have you smoked cigarettes in the past month?' and 'Have you ever smoked?'. According to these two questions, all adults were divided into three mutually exclusive smoking-status groups: non-smokers, current smokers, and former smokers. Second, regular drinking was defined as a dummy variable. The CFPS question supporting this variable was: 'Have you often drunk alcohol more than 3 times a week?'.

The adults answered 'Yes' coding as 1 and 'No' coding as 0 . Third, a person can be classified as unhealthy weight based on body mass index (BMI). The BMI was calculated according to the CFPS questions: 'What is your height (centimeters)?' and 'How much is your weight (0.5 kilograms)?'. For further analysis, the BMI was categorized into the following four groups according to World Health Organization Asian BMI cut points: underweight $(<18.5)$, healthy weight (18.5-22.9), overweight (23.0-27.5), and obesity $(>27.5)[31]$.

Last, to control the possible effect of confounding factors, control variables were selected based on the emerging behavioral model of health services use, and this model requires longitudinal study designs [32]. Predisposing factors in this study were age, gender, marital status, and urban residency. Enabling factors included household incomes, medical insurance, educational attainment, and employment status. Perceived need factors 
were represented by self-reported health status and chronic disease. Definitions of all variables are provided in Table 1.

Table 1. Definitions of Variables

\begin{tabular}{|c|c|}
\hline Variable & Description \\
\hline \multicolumn{2}{|l|}{ Dependent variable } \\
\hline Outpatient care utilization & $\begin{array}{l}\text { Coded: } 1 \text { if the individual self-reported an outpatient visit in } \\
\text { the last two weeks; } 0 \text { otherwise }\end{array}$ \\
\hline Inpatient care utilization & $\begin{array}{l}\text { Coded: } 1 \text { if the individual self-reported hospitalization in the } \\
\text { past twelve months; } 0 \text { otherwise }\end{array}$ \\
\hline \multicolumn{2}{|l|}{ Independent variables } \\
\hline \multicolumn{2}{|l|}{ Smoking status } \\
\hline Current smoker & $\begin{array}{l}\text { Coded: } 1 \text { if the individual who currently smokes tobacco } \\
\text { products; } 0 \text { otherwise }\end{array}$ \\
\hline Former smoker & Coded: 1 if the individual who had quit smoking; 0 otherwise \\
\hline Never smoker & Coded: 1 if the individual who has never smoked; 0 otherwise \\
\hline Regular drinking & $\begin{array}{l}\text { Coded: } 1 \text { if the individual drinks alcohol more than } 3 \text { times a } \\
\text { week in the past month; } 0 \text { otherwise }\end{array}$ \\
\hline \multicolumn{2}{|l|}{ BMI groups } \\
\hline Underweight & Coded: 1 if the individual's BMI $<18.5 ; 0$ otherwise \\
\hline Healthy weight & $\begin{array}{l}\text { Coded: } 1 \text { if the individual's BMI between 18.5-22.9; } 0 \\
\text { otherwise }\end{array}$ \\
\hline Overweight & $\begin{array}{l}\text { Coded: } 1 \text { if the individual's BMI between 23.0-27.5; } 0 \\
\text { otherwise }\end{array}$ \\
\hline Obesity & Coded: 1 if the individual's BMI $>27.5 ; 0$ otherwise \\
\hline \multicolumn{2}{|l|}{ Age group } \\
\hline $15-24$ & Coded: 1 if the individual is $15-24$ years old; 0 otherwise \\
\hline $25-64$ & Coded: 1 if the individual is $25-64$ years old; 0 otherwise \\
\hline$>=65$ & Coded: 1 if the individual is $>=65$ years old; 0 otherwise \\
\hline Male & Coded: 1 if the individual is male; 0 for female \\
\hline \multicolumn{2}{|l|}{ Educational attainment } \\
\hline Illiteracy & Coded: 1 if the individual is illiterate; 0 otherwise \\
\hline Elementary school & $\begin{array}{l}\text { Coded: } 1 \text { if the individual attends elementary school; } 0 \\
\text { otherwise }\end{array}$ \\
\hline Middle school & $\begin{array}{l}\text { Coded: } 1 \text { if the individual graduates from middle school; } 0 \\
\text { otherwise }\end{array}$ \\
\hline High school & $\begin{array}{l}\text { Coded: } 1 \text { if the individual graduates from high school; } 0 \\
\text { otherwise }\end{array}$ \\
\hline Above three-years of & Coded: 1 if the individual graduates from above three-year \\
\hline
\end{tabular}




\begin{tabular}{|c|c|}
\hline college & college; 0 otherwise \\
\hline Married & Coded: 1 if the individual is married; 0 otherwise \\
\hline Urban residency & Coded: 1 if the individual is urban resident; 0 for rural resident \\
\hline Medical insurance & $\begin{array}{l}\text { Coded: } 1 \text { if the individual enrolls a medical insurance scheme; } \\
0 \text { if the individual does not have medical insurance }\end{array}$ \\
\hline Household income & $\begin{array}{l}\text { Net household income (10,000 Yuan). The CFPS measured } \\
\text { comparable household income between } 2010 \text { to } 2018 \text {. }\end{array}$ \\
\hline Employed & $\begin{array}{l}\text { Coded: } 1 \text { if the individual reports participating agricultural } \\
\text { jobs, working with wages for an employer, or working for } \\
\text { oneself rather than an employer; } 0 \text { if the individual reports } \\
\text { being temporary worker, retirement, unemployment, or } \\
\text { student; }\end{array}$ \\
\hline \multicolumn{2}{|l|}{ Health status } \\
\hline Poor & $\begin{array}{l}\text { Coded: } 1 \text { if the individual reports health status to be poor; } 0 \\
\text { otherwise }\end{array}$ \\
\hline Fair & $\begin{array}{l}\text { Coded: } 1 \text { if the individual reports health status to be fair; } 0 \\
\text { otherwise }\end{array}$ \\
\hline Good & $\begin{array}{l}\text { Coded: } 1 \text { if the individual reports health status to be good, } \\
\text { very good, or excellent; } 0 \text { otherwise }\end{array}$ \\
\hline Chronic diseases & $\begin{array}{l}\text { Coded: } 1 \text { if the individual has had doctor-diagnosed chronic } \\
\text { diseases in the past six months; } 0 \text { otherwise }\end{array}$ \\
\hline
\end{tabular}

RMB: 1000 Chinese Renminbi about 150 US\$

\section{Statistical analysis}

The present study estimated the impact of smoking, regular drinking, and unhealthy weight on healthcare utilization employing logistic regression models and assumes that there is an unobserved variable $y_{i t}^{*}$ that called the latent variable.

$$
y_{i t}^{*}=x_{i t}^{\prime} \beta+\mu_{i}+e_{i t}
$$

where $x_{i t}$ is a vector of independent variables for an individual $i$ at time $t, \beta$ is the coefficient vector, $\mu_{i}$ is the unobserved and individual-specific heterogeneity, and $e_{i t}$ is a time-dependent error term. There is a binary variable $y_{i t}$ where

$$
y_{i t}=1 \text { if } y_{i t}^{*}>0 \text {, and } 0 \text { therwise }
$$


where $y_{i t}=1$ indicates that the individual visited outpatient care (or being hospitalized).

Then, the probability that $y_{1 i t}=1$ is

$$
\begin{gathered}
P\left(y_{i t}=1 \mid x_{i t}, \beta, \mu_{i}\right)=P\left(y_{i t}^{*}>0 \mid x_{i t}, \beta, \mu_{i}\right) \\
=P\left(x_{i t}^{\prime} \beta+\mu_{i}+e_{i t}>0 \mid x_{i t}, \beta, \mu_{i}\right) \\
=P\left(e_{i t}<\mu_{i}+x_{i t}^{\prime} \beta \mid x_{i t}, \beta, \mu_{i}\right) \\
=F\left(\mu_{i}+x_{i t}^{\prime} \beta\right)
\end{gathered}
$$

It assumes that the error term $e_{i t}$ is logistically distributed and we arrive the logistic regression model:

$$
\begin{aligned}
& P\left(y_{i t}=1 \quad \mid x_{i t}, \beta, \mu_{i}\right)=\frac{e^{\mu_{i}+x_{i t}^{\prime} \beta}}{1+e^{\mu_{i}+x_{i t}^{\prime} \beta}} \\
& P\left(\left(y_{i t}=0 \quad \mid x_{i t}, \beta, \mu_{i}\right)=\frac{1}{1+e^{\mu_{i}+x_{i t}^{\prime} \beta}}\right.
\end{aligned}
$$

Furthermore, the assumption that unobserved heterogeneity $\mu_{i}$ is uncorrelated with $x_{i t}$ produces the random effects logistic model. However, uncorrelated heterogeneity is not a very realistic assumption. When $\mu_{i}$ is correlated to $x_{i t}$, then it is called the fixed effects logistic model [27, 33].

Before considering the panel structure, the current study first used a pooled logistic model to analyze healthcare utilization. And then, this study treated the data as panel structure and employed the random effects logistic model. A likelihood ratio (LR) test could choose between pooled and random effects logistic model. Last, this study used the fixed effects logistic model, and Hausman's specification test could provide a way to compare the fixed effects and random effects model. 


\section{Results}

A descriptive summary of selected variables over time is displayed in Table 2. The proportions of visiting outpatient care increased from $18.37 \%$ in 2010 to $27.01 \%$ in 2018 . Hospitalization rates sharply increased from $7.33 \%$ in 2010 to $15.05 \%$ in 2018 . These results indicated an increasing tendency for healthcare utilization. About one in three respondents were current smokers from 2010 to 2018. Moreover, the proportions of former smokers rose from $6.16 \%$ in 2010 to $12.22 \%$ in 2018 . Approximately $17.0 \%$ of respondents were regular drinkers from 2010 to 2018 . The proportions of overweight and obesity were $35.24 \%$ and $7.41 \%$ in 2010 . These proportions increased to $41.84 \%$ and $12.13 \%$ in 2018 , respectively.

Table 2. Description of selected variables in five waves

\begin{tabular}{cccccc}
\hline & $\begin{array}{c}\text { Wave 1 } \\
\mathbf{2 0 1 0}\end{array}$ & $\begin{array}{c}\text { Wave 2 } \\
\mathbf{2 0 1 2}\end{array}$ & $\begin{array}{c}\text { Wave 3 } \\
\mathbf{2 0 1 4}\end{array}$ & $\begin{array}{c}\text { Wave 4 } \\
\mathbf{2 0 1 6}\end{array}$ & $\begin{array}{c}\text { Wave 5 } \\
\mathbf{2 0 1 8}\end{array}$ \\
\hline Outpatient care utilization (\%) & & & & & \\
Yes & 18.37 & 20.90 & 24.19 & 24.03 & 27.01 \\
No & 81.63 & 79.10 & 75.81 & 75.97 & 72.99 \\
Inpatient care utilization (\%) & & & & & \\
Yes & 7.33 & 8.60 & 10.95 & 12.94 & 15.05 \\
No & 92.67 & 91.40 & 89.05 & 87.06 & 84.95 \\
Smoking status (\%) & & & & & \\
Never smokers & 62.70 & 60.50 & 59.52 & 58.93 & 58.52 \\
Current smokers & 31.14 & 30.58 & 29.87 & 28.58 & 29.26 \\
Former smokers & 6.16 & 8.92 & 10.61 & 12.49 & 12.22 \\
Regular drinking (\%) & & & & & \\
Yes & 16.77 & 16.99 & 17.04 & 16.46 & 16.88 \\
No & 83.23 & 83.01 & 82.96 & 83.54 & 83.12 \\
Body mass index (\%) & & & & & \\
Underweight & 7.63 & 7.88 & 6.81 & 6.66 & 5.53 \\
Healthy weight & 49.73 & 46.70 & 43.85 & 42.43 & 40.50 \\
Overweight & 35.24 & 36.26 & 39.10 & 39.42 & 41.84 \\
\hline & & & & & \\
\hline
\end{tabular}




\begin{tabular}{cccccc}
\hline Obesity & 7.41 & 9.16 & 10.24 & 11.50 & 12.13 \\
Observations & 12,652 & 12,652 & 12,652 & 12,652 & 12,652 \\
\hline
\end{tabular}

Table 3 presents the regression analysis results for the pooled logistic, random effects logistic, and fixed effects logistic model (outpatient care utilization). Since the likelihood ratio test showed a highly significant test statistics $(L R=1086.53)$ for the random effects logistic model, unobserved heterogeneity was significant, and panel estimation methods were needed in this study. The Hausman's specification test showed a test statistic $\chi^{2}(20)=1268.40$, which was significant at the $1 \%$ level. Hence, according to the Hausman test, fixed effects estimates should be preferred over random effects estimates.

The results of the logistic regression analysis are showed in Table 3 as odds ratios. An odds ratio (OR) greater than one indicates a positive effect on the likelihood of using outpatient care; an odds ratio less than one indicates a negative effect. Column (iii) of Table 3 presents factors affecting outpatient care utilization using the fixed effects logistic model. The results presented that smoking status was related to the use of outpatient care. Current and former smokers were approximately 1.9 times and 2.0 times more likely to use outpatient care compared to those who never smoked $(\mathrm{OR}=1.884, \mathrm{p}<0.01 ; \mathrm{OR}=2.034$, $\mathrm{p}<0.01)$. Moreover, compared to current smokers, former smokers increased the odds of using outpatient care $(\mathrm{OR}=2.034>\mathrm{OR}=1.884)$. People who regularly drank alcohol were about 0.8 times less likely to use outpatient care than non-regular drinkers $(\mathrm{OR}=0.833$, $\mathrm{p}<0.01)$. Obese people were associated with a $25.8 \%$ increase in the odds of using outpatient care than healthy weight people $(\mathrm{OR}=1.258, \mathrm{p}<0.01)$. 
Irrespective of the estimation method, current and former smokers increased the likelihood of using outpatient care than never smokers. In contrast, regular drinkers decreased the likelihood of using outpatient care than non-drinkers (see Column (i)- (iii) of Table 3).

Table 3. Logistic regression analysis of outpatient care utilization

\begin{tabular}{|c|c|c|c|}
\hline & Pooled logistic & $\begin{array}{c}\text { Random effects } \\
\text { logistic }\end{array}$ & $\begin{array}{l}\text { Fixed effects } \\
\text { logistic }\end{array}$ \\
\hline & $\begin{array}{c}\text { (i) } \\
\text { Odd Ratios (SE) }\end{array}$ & $\begin{array}{c}\text { (ii) } \\
\text { Odd Ratios (SE) }\end{array}$ & $\begin{array}{c}\text { (iii) } \\
\text { Odd Ratios (SE) }\end{array}$ \\
\hline \multicolumn{4}{|l|}{ Smoking status } \\
\hline Current smoker & $1.116^{* * *}(0.0468)$ & $1.163 * * *(0.0533)$ & $1.884 * * *(0.275)$ \\
\hline Former smoker & $1.116^{* *}(0.0580)$ & $1.195 * * *(0.0664)$ & $2.034 * * *(0.309)$ \\
\hline \multicolumn{4}{|l|}{ Never smoker (ref.) } \\
\hline Regular drinking & $0.822 * * *(0.0307)$ & $0.804 * * *(0.0317)$ & $0.833^{* * *}(0.0447)$ \\
\hline \multicolumn{4}{|l|}{ BMI groups } \\
\hline \multicolumn{4}{|l|}{$\begin{array}{l}\text { Healthy weight } \\
\text { (ref.) }\end{array}$} \\
\hline Underweight & $1.110 * *(0.0507)$ & $1.132 * *(0.0565)$ & $1.086(0.0712)$ \\
\hline Overweight & $0.960(0.0254)$ & $0.962(0.0277)$ & $1.016(0.0434)$ \\
\hline Obesity & $0.992(0.0416)$ & $1.032(0.0475)$ & $1.258^{* * *}(0.0964)$ \\
\hline \multicolumn{4}{|l|}{ Age group } \\
\hline \multicolumn{4}{|l|}{ 15-24 (ref.) } \\
\hline $25-64$ & $1.552 * * *(0.130)$ & $1.582 * * *(0.143)$ & $1.168(0.150)$ \\
\hline$>=65$ & $1.981 * * *(0.174)$ & $2.205 * * *(0.210)$ & $1.686 * * *(0.240)$ \\
\hline Male & $0.711 * * *(0.0284)$ & $0.653 * * *(0.0288)$ & - \\
\hline \multicolumn{4}{|l|}{$\begin{array}{l}\text { Educational } \\
\text { attainment } \\
\text { Illiteracy(ref.) }\end{array}$} \\
\hline Elementary school & $0.880 * * *(0.0305)$ & $0.853^{* * *}(0.0329)$ & $0.982(0.0885)$ \\
\hline Middle school & $0.852 * * *(0.0296)$ & $0.816 * * *(0.0316)$ & $1.036(0.131)$ \\
\hline High school & $0.792 * * *(0.0358)$ & $0.747 * * *(0.0376)$ & $1.158(0.210)$ \\
\hline $\begin{array}{l}\text { Above three-years } \\
\text { of college }\end{array}$ & $0.762 * * *(0.0466)$ & $0.703 * * *(0.0471)$ & $1.197(0.271)$ \\
\hline Married & $0.963(0.0405)$ & $0.945(0.0444)$ & $0.822 * *(0.0726)$ \\
\hline Urban residency & $0.904 * * *(0.0246)$ & $0.912 * * *(0.0273)$ & $1.255^{* * *}(0.0929)$ \\
\hline Medical insurance & $1.180 * * *(0.0482)$ & $1.192 * * *(0.0526)$ & $1.116^{* *}(0.0563)$ \\
\hline
\end{tabular}




\begin{tabular}{lccc}
\hline Household income & $1.001(0.00142)$ & $1.003(0.00190)$ & $1.010 * * *(0.00305)$ \\
$\begin{array}{l}\text { Employed } \\
\text { Health status }\end{array}$ & $1.142 * * *(0.0325)$ & $1.175^{* * *}(0.0358)$ & $1.227 * * *(0.0489)$ \\
$\quad$ Poor & $3.071 * * *(0.0959)$ & $3.438^{* * *}(0.119)$ & $2.487 * * *(0.101)$ \\
$\quad$ & & \\
$\quad$ Fair (ref.) & & & \\
$\quad$ Good & $0.457 * * *(0.0123)$ & $0.443 * * *(0.0131)$ & $0.570 * * *(0.0193)$ \\
Chronic disease & $3.092 * * *(0.0827)$ & $3.233 * * *(0.0930)$ & $2.209 * * *(0.0713)$ \\
Constant & $0.184 * * *(0.0167)$ & $0.147 * *(0.0147)$ & - \\
Observations & 63,260 & 63,260 & 34,520 \\
\hline
\end{tabular}

Note: Note: Likelihood ratio test in random effects logistic model: $L R=1086.53, p=0.000$ Hausman's specification test is not significant at 5\% level: $\chi^{2}(20)=1268.40, p=0.0000$ Asterisks $^{* * *}$ indicates statistical significance at the $1 \%$ level, ${ }^{* *}$ at the $5 \%$ level.

Table 4 shows the regression analysis results for the pooled logistic, random effects logistic, and fixed effects logistic model (inpatient care utilization). Based on the likelihood ratio test and the Hausman's specification test, the fixed effects estimation was the preferred method for panel data in this study.

Column (iii) of Table 4 presents factors affecting inpatient care utilization using the fixed effects logistic model. The results showed that compared to those who never smoked, current and former smokers increased the likelihood of being hospitalized by $42.2 \%$ and $198.2 \%$, respectively $(\mathrm{OR}=1.422 ; \mathrm{p}<0.1, \mathrm{OR}=2.982 ; \mathrm{p}<0.01)$. Furthermore, compared to current smokers, former smokers increased the odds of being hospitalized ( $\mathrm{OR}=2.982>$ $\mathrm{OR}=1.422$ ). People who regularly drank alcohol decreased the probability of being hospitalized than non-regular drinkers $(\mathrm{OR}=0.678, \mathrm{p}<0.01)$. Compared to healthy weight people, overweight and obese people were more likely to be hospitalized $(\mathrm{OR}=1.108$; $\mathrm{p}<0.1, \mathrm{OR}=1.180 ; \mathrm{p}<0.1)$ 
Irrespective of the estimation method, former smokers increased the likelihood of being hospitalized than never smokers. In contrast, regular drinkers decreased the likelihood of being hospitalized than non-regular drinkers (see Column (i)- (iii) of Table 4).

Table 4. Logistic regression analysis of inpatient care utilization

\begin{tabular}{|c|c|c|c|}
\hline & Pooled logistic & $\begin{array}{c}\text { Random effects } \\
\text { logistic }\end{array}$ & $\begin{array}{l}\text { Fixed effects } \\
\text { logistic }\end{array}$ \\
\hline & $\begin{array}{c}\text { (i) } \\
\text { Odd Ratios (SE) }\end{array}$ & $\begin{array}{c}\text { (ii) } \\
\text { Odd Ratios (SE) }\end{array}$ & $\begin{array}{c}\text { (iii) } \\
\text { Odd Ratios (SE) }\end{array}$ \\
\hline \multicolumn{4}{|l|}{ Smoking status } \\
\hline Current smoker & $1.003(0.0515)$ & $1.015(0.0555)$ & $1.422^{*}(0.265)$ \\
\hline Former smoker & $1.602^{* * *}(0.0906)$ & $1.783^{* * *}(0.111)$ & $2.982^{* * *}(0.573)$ \\
\hline \multicolumn{4}{|l|}{ Never smoker (ref.) } \\
\hline Regular drinking & $0.793^{* * *}(0.0361)$ & $0.759^{* * *}(0.0372)$ & $0.678^{* * *}(0.0459)$ \\
\hline \multicolumn{4}{|l|}{ BMI groups } \\
\hline \multicolumn{4}{|l|}{$\begin{array}{l}\text { Healthy weight } \\
\text { (ref.) }\end{array}$} \\
\hline Underweight & $0.956(0.0546)$ & $0.954(0.0595)$ & $0.965(0.0820)$ \\
\hline Overweight & $1.013(0.0334)$ & $1.027(0.0361)$ & $1.108^{*}(0.0590)$ \\
\hline Obesity & $1.055(0.0552)$ & $1.070(0.0587)$ & $1.180^{*}(0.109)$ \\
\hline \multicolumn{4}{|l|}{ Age group } \\
\hline \multicolumn{4}{|l|}{$15-24$ (ref.) } \\
\hline $25-64$ & $1.096(0.118)$ & $1.081(0.119)$ & $0.873(0.132)$ \\
\hline$>=65$ & $2.046^{* * * *}(0.225)$ & $2.169^{* * *}(0.247)$ & $1.527^{* *}(0.256)$ \\
\hline Male & $0.920^{*}(0.0441)$ & $0.887^{* *}(0.0461)$ & - \\
\hline \multicolumn{4}{|l|}{$\begin{array}{l}\text { Educational } \\
\text { attainment } \\
\text { Illiteracy(ref.) }\end{array}$} \\
\hline Elementary school & $0.888^{* * *}(0.0383)$ & $0.880^{* * *}(0.0408)$ & $1.142(0.127)$ \\
\hline Middle school & $0.873^{* * *}(0.0382)$ & $0.851^{* * *}(0.0399)$ & $1.068(0.170)$ \\
\hline High school & $0.993(0.0558)$ & $0.974(0.0575)$ & $1.311(0.302)$ \\
\hline $\begin{array}{l}\text { Above three-years } \\
\text { of college }\end{array}$ & $0.834^{* *}(0.0648)$ & $0.782^{* * *}(0.0633)$ & $1.103(0.340)$ \\
\hline Married & $1.014(0.0558)$ & $1.012(0.0560)$ & $0.967(0.103)$ \\
\hline Urban residency & $1.130^{* * *}(0.0380)$ & $1.149^{* * *}(0.0413)$ & $1.286^{* * *}(0.120)$ \\
\hline Medical insurance & $1.680^{* * *}(0.0948)$ & $1.695^{* * *}(0.103)$ & $1.452^{* * *}(0.101)$ \\
\hline
\end{tabular}




\begin{tabular}{lccc}
\hline Household income & $1.002(0.00132)$ & $1.002(0.00201)$ & $1.005(0.00364)$ \\
Employed & $0.916^{* *}(0.0315)$ & $0.921^{* *}(0.0335)$ & $0.991(0.0491)$ \\
Health status & & & \\
$\quad$ Poor & $2.220^{* * *}(0.0879)$ & $2.382^{* * *}(0.101)$ & $1.938^{* * *}(0.0986)$ \\
$\quad$ & & & \\
$\quad$ Fair (ref.) & & & \\
$\quad$ Good & $0.695^{* * *}(0.0251)$ & $0.687^{* * *}(0.0267)$ & $0.788^{* * *}(0.0354)$ \\
Chronic disease & $2.813^{* * *}(0.0880)$ & $2.986^{* * *}(0.100)$ & $2.313^{* * *}(0.0904)$ \\
Constant & $0.0492^{* * *}$ & $0.0353^{* * *}(0.00443)$ & - \\
& $(0.00569)$ & & \\
Observations & 63,260 & 63,260 & 22,650 \\
\hline
\end{tabular}

Note: Note: Likelihood ratio test in random effects logistic model: $L R=622.00, p=0.000$ Hausman's specification test is not significant at 5\% level: $\chi^{2}(20)=303.22, p=0.0000$ Asterisks ${ }^{* * *}$ indicates statistical significance at the $1 \%$ level, ${ }^{* *}$ at the $5 \%$ level, ${ }^{*}$ at the $10 \%$ level.

\section{Discussion}

The aim of this study was to ascertain the effects of smoking, regular drinking, and unhealthy weight on healthcare utilization in China using a five-waves of balanced panel data set. First, this study found that among Chinese adults, current and former smokers were more likely to use outpatient and inpatient care compared to those who never smoked. The explanation is straightforward. Smoking has adverse health effects and causes acute and chronic diseases and, therefore, may require more healthcare utilization. Moreover, the current study found that compared to current smokers, former smokers increased the odds of using outpatient and inpatient care. Former smokers use more healthcare services simply because many of them stopped smoking due to health concerns and serious illnesses they experienced.

Previous studies found that smokers commonly bear higher healthcare costs than those 
who never smoked [34-36]. China successfully achieved universal health insurance coverage, and approximately $95 \%$ of the population was insured in 2011 . However, the sources of financing health insurance plans are no different between smokers and nonsmokers. Therefore, people who never smoked may subsidize the health care costs of smokers. The Chinese government should consider raising taxes on tobacco, which not only reduces the smoking prevalence but also increases revenues. These increased revenues can financially sustain public health insurance plans.

Second, the current study found that among Chinese adults, people who regularly drank alcohol were less likely to use outpatient and inpatient care than non-regular drinkers. The result is consistent with findings for American drinkers [19], rural Liberia drinkers [20], and German drinkers [37]. Three possible reasons may explain the inverse relationship between regular drinking and healthcare utilization: firstly, people who regularly drink alcohol may not care about their health status or maybe risk-tolerant individuals $[22,38]$. Secondly, the adverse health consequence of drinking may appear several years later. Lastly, alcohol is frequently used by men in China, and Chinese cultural norms encourage social drinking, especially with friends and family [39]. Non-drinkers in such a cultural or social situation may be related to alcohol allergy and intolerance, and hence they may use more healthcare services [40]. It is worth noting that people who regularly drink alcohol experience omitted or delayed healthcare, leading to serious health problems and higher healthcare costs on society [22]. The Chinese government should conduct screening and brief advice programs delivered by primary level care, reducing the 
burden of diseases due to regular drinking.

Third, the present study found that among Chinese adults, obese people increased the likelihood of using outpatient and inpatient care than healthy weight people. In addition, overweight people were more likely to be hospitalized than healthy weight people. Higher morbidity associated with being overweight and obesity has been observed for hypertension, diabetes, coronary heart disease, stroke, and cancers [41]. Hence, higher healthcare utilization may be needed to treat these conditions. The Chinese government should promote a national public education campaign to encourage overweight and obese people to maintain a healthy weight, improving their health status, and saving considerable healthcare costs.

There are several limitations that should be emphasized. First, this study measured outpatient care utilization based on the question: 'Did you visit a doctor in the past two weeks?', and it might underestimate the utilization of outpatient care among Chinese adults. Second, self-reported smoking status, drinking status, height, and weight were used in this study, thus sharing the limitations of all self-reported data: recall bias and unreliable under pressure. Third, this study could not exclude ex-drinkers from the group of nonregular drinkers. If ex-drinkers stopped drinking due to severe illnesses, it might affect the inverse association between regularly drinking and healthcare utilization. Last, when the respondents without change of healthcare utilization decision in all five waves do not contribute to the likelihood, the fixed effects model lost many pieces of information. Therefore, the estimated results would be less precise and having larger standard errors. 


\section{Conclusions}

The purpose of this study is to empirically ascertain the effects of smoking, regular drinking, and unhealthy weight on healthcare utilization in China. The empirical findings suggest that among Chinese adults, current and former smokers were more likely to use health care compared to those who never smoked. Moreover, obese and overweight people increased the likelihood of using health care than healthy weight people. Interestingly, people who regularly drank alcohol were less likely to use outpatient and inpatient care than non-regular drinkers. These results may have important implications for supporting the government to make healthcare resources allocation decisions.

\section{List of abbreviations}

CFPS: China Family Panel Studies; BMI: Body Mass Index; LR: Likelihood Ratio; OR:

Odds Ratio

\section{Declarations}

\section{Ethics approval and consent to participate}

For this research, we have used publicly available secondary data set with all individual identifiers removed prior to making the data set available publicly. No ethical approval was required due to the type and nature of data set used.

\section{Consent for publication}

No applicable.

\section{Availability of data and materials}


The datasets generated and/or analysed during the current study are available in the Peking $\begin{array}{llll}\text { University } & \text { Open } & \text { Research } & \text { Data }\end{array}$ repository, https://opendata.pku.edu.cn/dataset.xhtml?persistentId=doi:10.18170/DVN/45

\section{LCSO.}

\section{Competing interests}

The authors declare that they have no competing interests.

\section{Funding}

This research was funded by the 2019 Project of Total Health Expenditure Accounting in Inner Mongolia, China.

\section{Authors' Contributions}

YC designed the study and developed the methodology. CL led the data analysis and wrote the manuscript. ZM made important contributions to the revision of the manuscript. All authors read and approved the final manuscript.

\section{References}

1. The Chinese National Health Commission. The Nutrtion and Chronic Disease of the Chinese Population (2015 report). Available online: http://www.nhc.gov.cn/jkj/s5879/201506/4505528e65f3460fb88685081ff158a2.s html (accessed on 15 Sep. 2020). 
2. Wang Y, Wang L, Qu W. New national data show alarming increase in obesity and noncommunicable chronic diseases in China. Eur. J. Clin. Nutr. 2017, 71, 149-150.

3. Sturm R. The effects of obesity, smoking, and drinking on medical problems and costs. Health Aff. 2002, 21, 245-253.

4. Bloom DE, Chen S, Kuhn M, McGovern ME, Oxley L, Prettner K. The economic burden of chronic diseases: estimates and projections for China, Japan, and South Korea. J. Econ. Ageing 2018, 100163.

5. Wagner EH, Curry SJ, Grothaus L, Saunders KW, McBride CM. The impact of smoking and quitting on health care use. Arch. Intern. Med. 1995, 155, 1789-1795.

6. Wacker M, Holle R, Heinrich J, Ladwig KH, Peters A, Leidl R, Menn P. The association of smoking status with healthcare utilisation, productivity loss and resulting costs: results from the population-based KORA F4 study. BMC Health Serv. Res. 2013, 13, 278.

7. Kahende JW, Adhikari B, Maurice E, Rock V, Malarcher A. Disparities in health care utilization by smoking status-NHANES 1999-2004. Int. J. Environ. 2009, 6, 1095-1106.

8. Li C, Fan Y, Supakankunti S. The impact of cigarette smoking on healthcare utilization among rural residents in China. J. Subst. Use 2018, 23, 626-633.

9. Gutzwiller F, La CV, Levi F, Negri E, Wietlisbach V. Smoking, prevalence of disease and health service utilization among the Swiss population. Rev. Epidemiol. Sante. Publique 1989, 37, 137-142. 
10. Azagba S, Sharaf MF, Liu CX. Disparities in health care utilization by smoking status in Canada. Int. J. Public Health 2013, 58, 913-925.

11. Izumi Y, Tsuji I, Ohkubo T, Kuwahara A, Nishino, Y, Hisamichi S. Impact of smoking habit on medical care use and its costs: a prospective observation of National Health Insurance beneficiaries in Japan. Int. J. Epidemiol. 2001, 30, 616621.

12. Jorm LR, Shepherd LC, Rogers KD, Blyth FM. Smoking and use of primary care services: findings from a population-based cohort study linked with administrative claims data. BMC Health Serv. Res. 2012, 12, 263.

13. Artalejo FR, de Andrés Manzano B, Guallar-Castillón P, Mendizabal MTP, Enrjquez JG, del Rey Calero J. The association of tobacco and alcohol consumption with the use of health care services in Spain. Prev. Med. 2000, 31, 554-561.

14. Haapanen-Niemi N, Miilunpalo S, Vuori I, Pasanen M, Oja P. The impact of smoking, alcohol consumption, and physical activity on use of hospital services. Am. J. Public Health 1999, 89, 691-698.

15. Alexandre P, Roebuck M, French M, Chitwood D, McCoy C. Problem Drinking, Health Services Utilization, and the Cost of Medical Care, in Alcoholism: Services Research in the Era of Managed Care Organization Access Economics Outcome. 2001, Springer US: Boston, MA. pp.285-298. 
16. Cherpitel CJ, Ye Y. Drug use and problem drinking associated with primary care and emergency room utilization in the US general population: data from the 2005 national alcohol survey. Drug Alcohol Depend. 2008, 97, 226-230.

17. Zarkin GA, Bray JW, Babor TF, Higgins-Biddle JC. Alcohol drinking patterns and health care utilization in a managed care organization. Health Serv. Ses. 2004, 39, $553-570$.

18. Polen MR, Green CA, Freeborn DK, Mullooly JP, Lynch F. Drinking patterns, health care utilization, and costs among HMO primary care patients. J Behav Health Ser. Res. 2001, 28, 378-399.

19. Armstrong MA, Midanik LT, Klatsky AL. Alcohol consumption and utilization of health services in a health maintenance organization. Med. Care 1998, 1599-1605.

20. Weil AA, Cameron CM, Soumerai J, Dierberg KL, Mouwon AG, Kraemer DR, Lewy D, Lee PT, Kraemer JD, Siedner MJ. Alcohol use and health care utilization in rural Liberia: Results of a community-based survey for basic public health indicators. Int. J. Alcohol Drug Res. 2014, 3, 169-181.

21. Edwards CH.; Aas E, Kinge JM. Body mass index and lifetime healthcare utilization. BMC Health Serv. Res. 2019, 19, 696.

22. Vals K, Kiivet RA, Leinsalu M. Alcohol consumption, smoking and overweight as a burden for health care services utilization: a cross-sectional study in Estonia. BMC Public Health 2013, 13, 772. 
23. Bertakis KD, Azari R. The influence of obesity, alcohol abuse, and smoking on utilization of health care services. Fam. Med. 2006, 38, 427.

24. Musich S, MacLeod S, Bhattarai GR, Wang SS, Hawkins K, Bottone Jr FG, Yeh CS. The impact of obesity on health care utilization and expenditures in a medicare supplement population. Gerontol Geriatr. Med. 2016, 2, 1-9.

25. Lartey ST, de Graaff B, Magnussen CG, Boateng GO, Aikins M, Minicuci N, et al. Health service utilization and direct healthcare costs associated with obesity in older adult population in Ghana. Health Policy Plan. 2020, 35, 199-209.

26. Takahashi PY, St Sauver JL, Olson TC, Huber JM, Cha SS, Ebbert JO. Association between underweight and hospitalization, emergency room visits, and mortality among patients in community medical homes. Risk Manag. Healthc. Policy 2013. $6,1-6$.

27. Greene WH. Econometric analysis. 2003: Pearson Education India.

28. Wooldridge JM. Introductory econometrics: A modern approach. 2016: Nelson Education.

29. Jiang H, Petersen PE, Peng B, Tai B, Bian Z. Self-assessed dental health, oral health practices, and general health behaviors in Chinese urban adolescents. Acta Odontol. Scand. 2005, 63, 343-352.

30. Xie Y, Hu J. An introduction to the China family panel studies (CFPS). Chin. Sociol. Rev. 2014, 47, 3-29. 
31. WHO Exper Consultation. Appropriate body-mass index for Asian populations and its implications for policy and intervention strategies. Lancet 2004, 363,157-163.

32. Andersen RM. Revisiting the behavioral model and access to medical care: does it matter? J. Health Soc. Behav. 1995, 36, 1-10.

33. Andreß HJ, Golsch K, Schmidt AW. Applied panel data analysis for economic and social surveys. 2013: Springer Science \& Business Media.

34. Barendregt JJ, Bonneux L, van der Maas PJ. The health care costs of smoking. N. Eng. J. Med. 1997, 337, 1052-1057.

35. Max W. The financial impact of smoking on health-related costs: a review of the literature. Am. J. Health Promot. 2001, 15, 321-331.

36. Goodchild M, Nargis N, d'Espaignet ET. Global economic cost of smokingattributable diseases. Tob. Control 2018, 27, 58-64.

37. Baumeister SE, Meyer C, Carreon D, Freyer J, Rumpf HJ, Hapke U, et al. Alcohol Consumption and Health-Services Utilizationin Germany. J. Stud. Alcohol 2006, 67, 429-435.

38. Dave D, Saffer H. Alcohol demand and risk preference. J. Econ. Psychol. 2008, 29, 810-831.

39. Cochrane J, Chen H, Conigrave KM, Hao W. Alcohol use in China. Alcohol Alcohol. 2003, 38, 537-542. 
40. Katerndahl DA, Bell IR, Palmer RF, Miller CS. Chemical intolerance in primary care settings: prevalence, comorbidity, and outcomes. Ann. Fam. Med. 2012, 10, $357-365$.

41. Clinical guidelines on the identification, evaluation, and treatment of overweight and obesity in adults: the evidence report. National Institutes of Health. Obes. Res.1998,suppl 2, 52s-209s. 